\title{
Helene Deutsch, pionera en el acercamiento a la psico(pato)logía de la mujer desde la perspectiva psicoanalítica
}

RESUMEN: Helene Deutsch fue una pionera en el acercamiento a la psico(pato)logía de la mujer desde la perspectiva psicoanalítica, aunque arrastró algunas limitaciones en sus ideas en parte por la fidelidad que le tenía a Sigmund Freud y en parte por sus propias conflictivas neuróticas. En todo caso, llamó la atención sobre la influencia de los factores culturales en el establecimiento del sistema sexo-género y en variados trastornos específicos de la mujer, superando la tesis falocéntrica freudiana. A pesar de ello algunas feministas de su época la consideraron una traidora de la causa femenina.

PALABRAS CLAVES: Helene Deutsch, psicología de la mujer, psicoanálisis, feminismo, sexo-género, narcisismo.

\begin{abstract}
Helene Deutsch was a pioneer in the approach to wards woman=s psycho(patho)logy from a psychoanalytic perspective.,Although her theory continued with some limitations in part because of her fidelity to Sigmund Freud and in part by her neurotic problems. In any case she attracted attention about the influence of cultural factors on the establishment of the sex-gender system and some specific disorders related to woman going beyond the freudian phalluscentric thesis. In spite of that, some feminists of her time considered her to be a traitor of the feminine cause.
\end{abstract}

KEYWORDS: Helene Deutsch, womanpsychology, sex-gender, psychoanalysis, feminism.

\section{Introducción.-}

Helene Deutsch se apoyó no sólo en el aprendizaje que logró al lado de Freud, sino también de las experiencias conflictivas que tuvo como hija y como madre, para enriquecer el conocimiento psicoanalítico de la mujer abriendo el camino que seguirían posteriormente, entre otros, Karen Horney (1), Clara Thompson (2) y Erik Erikson (3), en el sentido de superar la hipótesis biologista de las diferencias anatómico-sexuales y la envidia del pene como fundamentos de la psico(pato)logía propia de la mujer. En efecto, fue más allá de las tesis freudianas, apuntando hacia las influencias socio-culturales en el establecimiento de la identidad femenina, defendiendo de que la envidia del pene tendría su origen en la distinta valoración cultural del hombre y la mujer, que generalmente favorece al varón. A pesar de ello, no fue bien valorada por algunas feministas, como por ejemplo, Friedan (4) y Badinter (5), que la calificaron de traidora a su sexo, a causa de estimar que había seguido excesivamente atada al patrón falocéntrico freudiano, que 
consideraba a la mujer como una especie de varón castrado y masoquista, llena de envidia por los privilegios masculinos. Aunque es cierto que Helene mantuvo a lo largo de su vida una manifiesta fidelidad a Freud (que la analizó durante un año) y que éste la tuvo en alta consideración, quejándose amargamente cuando abandonó Europa para instalarse en Estados Unidos dado que perdía con ello a una de sus discípulas más notables, algunos pensamos hoy que, en contra de que lo que mantuvieron las referidas feministas, Helene fue una pionera de la línea de la intersubejtividad, al tener en cuenta los factores sociales en la crianza y educación para la instauración del llamado sistema sexo-género (6) y por otro lado dignificó la psicopatología de la mujer. Además, es mérito suyo el haber sido de los primeros clínicos que se ocuparon de lo que hoy denominamos trastornos de la personalidad, con un enfoque muy original, describiendo con elegancia los ingredientes narcisistas que laten en la mayor parte de tales anomalías.

\section{Una problemática infancia y una juventud rebelde}

Helene Deutsch (1884-1982), de soltera Rosenbach y familiarmente llamada Hala, nació el 9 de octubre de 1884 en Przemysl, ciudad que entonces pertenecía a la Galitzia polaca, situada en la frontera entre Ucrania y lo que en aquel tiempo era el Imperio austro-húngaro. Su familia pertenecía a la burguesía judía asimilada, siendo su padre Wilhelm Rosenbach juez y magistrado de distrito, así como representante de Galitzia en la Corte Federal de Viena, habiendo logrado mucho cariño y respeto de los polacos, tanto de los judíos como de los que no lo eran (7). La madre, Regina, era una señora muy ambiciosa, de carácter fuerte y distante, que deseaba para sus hijas una vida burguesa y convencional. El matrimonio tuvo cuatro hijos, Emil, Malvina, Gizela y nuestra Helene, la cual vino al mundo tras un intervalo de ocho años respecto a la anterior hermana (7). Su padre deseaba un varón que respondiera al ideal judío, tener un gran hombre por hijo, objetivo que su hijo Emil no cumplía (8). A pesar de ello, las relaciones de Helene con su padre fueron muy satisfactorias, pues superando la frustración inicial, fue aceptada por él como su heredera espiritual. Lo contrario ocurrió con su madre, que la rechazó de forma evidente desde el mismo nacimiento: los cuidados infantiles a que fue sometida, por ejemplo, corrieron a cargo nada menos que de nueve sucesivas nodrizas, ejerciendo la función de madre durante algún tiempo su hermana Malvina, once años mayor que ella. Sin embargo, perdió pronto a esta madre sustituta, pues cuando Helene contaba diez años, esta hermana se alejó del hogar al contraer matrimonio. En cuanto a las relaciones con sus hermanos varones fueron bastante problemáticas, especialmente con Emil, que al parecer abusó sexualmente de ella siendo muy niña, dato que ella refiere veladamente en su autobiografía, obra que apareció originalmente en inglés con el título Confrontaciones con mi self en la editorial neoyorquina Norton y en donde afirma que su más importante revolución fue liberarse de la tiranía de su madre (9).

Cuando Helene finalizó su escolarización contaba catorce años de edad y lo único que la madre tenía planeado para ella era un buen casamiento para que pudiese vivir en la ociosidad a costa del dinero que ganase el esposo. Helene se reveló contra esta 
HISTORIA

propuesta hasta el punto de fugarse de su casa, negociando su vuelta con la condición de que sus padres la ayudasen a realizar estudios universitarios cosa que consiguió, llegando a doctorarse en Medicina aunque su vocación inicial era la del Derecho, por influencia del padre al que a menudo acompañó a su bufete, donde escuchaba toda clase de problemas sociales y personales (9). Esto último fue una influencia decisiva para poner en marcha en sus años juveniles su compromiso político, llegando a actuar como militante socialista en la causa obrera.

En su línea de rebeldía y quizás como expresión de su conflictiva edípica, a los dieciséis años Helene se une sentimentalmente a un dirigente socialista casado y mucho mayor que ella, Herman Lieberman, relación que mantuvo en secreto para no perjudicar la reputación de éste. Paradójicamente a lo que era de esperar, Helene adoptó en esta relación una actitud bastante sumisa, sin presionar nunca a Herman para que pidiese el divorcio. Esta tortuosa historia se extendió a lo largo de unos cinco años, justamente hasta 1905, momento en que falleció uno de los hijos de Herman, lo que ocasionó un afianzamiento de su matrimonio. Con posterioridad, sin embargo, los encuentros entre ambos se reanudaron en Viena, llegando a quedar Helene embarazada de Herman, aunque abortó voluntariamente.

Por esta época, Helene participó en su ciudad natal en varias revueltas callejeras contra la policía, siendo la responsable de la organización de la primera huelga de mujeres en Przemysl. Con veintiún años se trasladó a Lwów (Lemberg) para preparar su ingreso en la Universidad, momento en que se derrumbó psíquicamente y ello motivó su ingreso en una clínica especializada en Graz (Austria), crisis que sin duda estuvo originada por las conflictivas relaciones afectivas que mantenía con Lieberman. En 1907, cuando Helene estudiaba Medicina en Viena, coincidió de nuevo con Herman, que entonces había sido nombrado miembro del Parlamento Austro-Húngaro en representación de Polonia en dicha ciudad, lo que volvió a poner en marcha los antiguos encuentros amorosos, con sus dudas y vaivenes.

\section{¡Una mujer que quiere ser psiquiatra!}

En 1907 Helene era una de las escasas mujeres que cursaban estudios universitarios en Viena. Por entonces, entre las variadas lecturas que llevó a cabo, le impresionó mucho la obra de Freud (10) acerca de la Gradiva de W. Jensen, al tener ante sí un novedoso mundo científico en el que se contaba con la sexualidad, tema tabú, y con el inconsciente, capítulo revolucionario para el saber psicológico de la época. Con posterioridad, en 1911, un amigo neurólogo, Josef Reinhold, le dio a leer La interpretación de los sueños (11), lo que la enganchó definitivamente con la teoría psicoanalítica, alternando durante algún tiempo su formación psiquiátrica y analítica, compromiso absolutamente atípico en aquella época en la que la mujer sólo era educada para ser madre, esposa y ama de casa, pudiendo aspirar si acaso a profesiones relacionadas con la crianza o la educación infantil. 
HISTORIA

Pero el asunto con Lieberman continuaba, aunque Helene se debatía en la ambivalencia, decidiendo finalmente trasladarse a Múnich para poner tierra por medio, lo que quizás vino motivado porque había quedado embarazada de aquél, como antes hemos referido. Helene comprendió que la naturaleza de la relación con Herman hacía imposible una adecuada maternidad y el logro de su autonomía, por lo que decidió abortar. Poco después se enamoraría de un joven y atractivo médico judío, Felix Deutsch, al parecer homosexual, con el que se casaría el 12 de abril de 1912, un año antes de que ella hubiese finalizado la carrera y el doctorado (12).

Helene fue abandonando progresivamente sus actividades políticas y ya con veintinueve años, tras haber culminado su doctorado en medicina, obtuvo su primer puesto de trabajo en un hospital para niños afectos de deficiencia mental, ya que inicialmente pensó en dedicarse a la pediatría. Muy pronto se percató, sin embargo, de que su vocación era la de psiquiatra, por lo que contactó con Wagner-Jauregg, el sucesor de Krafft-Ebing en la cátedra de enfermedades nerviosas de Viena y conocido enemigo del psicoanálisis. Bajo su tutela, logró especializarse en psiquiatría, pasando antes, en 1916, una temporada en Múnich, adscrita al programa de investigación de Emil Kraepelin, centrado en el tema de las asociaciones verbales (asunto que tendría un papel relevante en las investigaciones de Jung), momento en el que Helene empezó a entusiasmarse con las teorías freudianas.

Haciendo la especialidad, y dada la ausencia de hombres por estar en los frentes de guerra, Wagner-Jauregg le confió la responsabilidad del servicio de mujeres de su clínica psiquiátrica, cargo que por su condición femenina no podía desempeñar legalmente, por lo que no obtenía remuneración alguna (7). Durante es época Helene simultaneaba este trabajo con la asistencia a las reuniones de la Asociación Psicoanalíítica de Viena, con disgusto de Wagner-Jauregg, que criticaba constantemente en las reuniones académicas a Freud y a sus ideas. Helene Deutsch, a pesar de ello, persistió en su interés por el psicoanálisis, acudiendo como invitada a la Asociación Psicoanalítica de Viena a partir del 14 de noviembre de 1917, hasta ser elegida miembro adherente en la sesión del 13 de febrero de 1918, para lo cual presentó un comentario del artículo de Andreas-Salomé Anal y sexual (13). Por entonces, ya era miembro de derecho otra mujer, Hermine Hug-Hellmuth, iniciadora del psicoanálisis infantil.

El año anterior, el 29 de enero de 1917, había dado a luz a su único hijo, Martin Deutsch, tras haber tenido varias experiencias de falsos embarazos. La filiación de Martin se ha puesto en duda, rumoreándose que realmente era hijo de Paul Barnay, actor y director de teatro y amigo íntimo de los Deutsch (14). Este hijo le supuso una serie de conflictos por sus dificultades para desempeñar el rol de madre, como, por ejemplo, no poder amamantarlo, lo que resolvió comprando dos cabras que pastaban, para sorpresa de todos, en el jardín de la clínica de Wagner-Jauregg. Otra nota curiosa al respecto es que, cuando inició su análisis personal con Freud a finales de 1918, llevaba cada día a casa de éste una jarra de leche de cabra para que se repusiera Martha, la mujer de Freud, de una pulmonía. 
Al finalizar la contienda bélica mundial y volver los hombres del frente, Helene se vio obligada a abandonar su puesto de ayudante clínico en favor de Paul Schilder, lo que en parte también vino condicionado por la presión de Wagner-Jauregg para que dejase a Freud, quien mostraba una actitud muy crítica hacia la psiquiatría oficial. Cuando tuvo que marcharse de la clínica, Wagner-Jauregg le extendió un curioso certificado, fechado el 12 de noviembre de 1918, donde decía que la doctora Deutsch había desempeñado el cargo de casi ayudante, habida cuenta que no era legal que las mujeres desempeñasen tal responsabilidad (15).

Este año de 1918 fue decisivo en otros aspectos, como el ya referido nombramiento de miembro de la Asociación Psicoanalítica de Viena y el inicio de su análisis con Freud, tomando la hora que había dejado libre la señora de Radó. Su análisis personal se vio enmarcado en el modelo de la época, donde el trabajo de las conflictivas con la figura paterna era el eje central, por lo que fueron dejadas completamente de lado las temáticas relacionadas con sus problemas con la madre y la mala identificación con ella, así como las consiguientes dificultades para el ejercicio del papel de esposa y madre que Helene aquejó. Como anécdota al respecto ella misma cuenta (9) que en una sesión Freud se adormiló y se le cayó de la mano el puro que fumaba, lo que precisamente sucedió cuando le estaba hablando de sus problemas para encontrar una niñera que cuidara a su hijo Martin, concretamente para que se ocupara de enseñarle los hábitos de higiene, ya que se había dado en el niño una regresión en el control de los esfínteres. La anterior niñera, Paula, había sido despedida porque criticó a Helene los escasos cuidados maternales que daba a su hijo. No fue la única empleada doméstica con la que Helene tuvo problemas, refiriendo su hijo Martin que ello era probablemente la expresión sintomática de pasados conflictos con su madre y sus hermanos (12).

Coincidiendo en parte con su análisis con Freud, que tuvo que dar fin antes del año para dejar su tiempo a Serguéi Pankejeff, el Hombre de los lobos, Helene tuvo bajo tratamiento psicoanalítico durante unos meses a Viktor Tausk, lo que originó un extraño triángulo Tausk-Deutsch-Freud. Tal análisis se interrumpió bruscamente a los tres meses de iniciado por indicación del propio Freud, que veía como el trabajo con Helene se iba convirtiendo en un análisis mediado de Viktor, al que no apreciaba mucho y al que se había negado a analizar. Tausk se suicidaría el 3 de julio de $1919(15,16)$.

\section{Estancia en Berlín para analizarse con Karl Abraham}

Durante la celebración del VI Congreso Internacional de Psicoanálisis de 1920, Helene tuvo ocasión de escuchar la comunicación de Karl Abraham sobre el complejo de castración y la envidia del pene de las mujeres, sorprendiéndose mucho que Freud no se hubiese ocupado durante su análisis de estos asuntos. Esto motivó que tres años después iniciara un análisis con Abraham, exactamente a partir de enero de 1923. Al respecto se sabe que Freud influyó en éste para que no alterase la débil estabilidad del matrimonio Deutsch, pues era consciente de que no tenía la solidez suficiente (12). 
En Berlín, además de analizarse con Abraham, Helene contactó con el Instituto local de formación, coincidiendo en la misma pensión con Melanie Klein, también analizada de Abraham, de la que no sacó una buena opinión, calificando sus aportaciones al análisis infantil de extremadamente especulativas (16).

Por entonces aparece en Deutsch un fuerte interés por la psicología de la mujer, como lo demuestra el contenido de la conferencia que dictó el 21 de abril de 1924 en el VIII Congreso Internacional de Psicoanálisis celebrado en Salzburgo (Austria). Su comunicación llevaba por título La psicología de la mujer con relación a las funciones de reproducción, que fue la base para la redacción del libro Psicoanálisis de las funciones sexuales de la mujer (17), donde abordó la sexualidad infantil de la niña, el complejo masculino de la mujer, la diferenciación entre el período reproductivo del varón y la mujer, la psicología de la pubertad, la desfloración, la psicología del acto sexual, el embarazo, el parto, la frigidez, la esterilidad, la lactancia y la menopausia. La existencia de síntomas en todo estos procesos fue interpretada por Deutsch como fruto de conflictos entre el amor narcisista y el amor maternal hacia los otros, superando así el enfoque freudiano y abrahamiano en torno a la conflictiva con el complejo de castración y la subsiguiente envidia del pene. El libro, sin embargo, fue criticado negativamente por Horney, porque a ésta le desagradó el masoquismo que Deutsch atribuía a la mujer, aunque señaló como aspecto positivo que era el primer trabajo que se ocupaba específicamente de la psicología femenina desde el ángulo psicoanalítico (1).

Helene, en efecto, en su teorización inicial se mostraba excesivamente sumisa a lo marcado por Freud $(18,19)$ respecto a la psicología de la mujer, aceptando, por ejemplo, los dos estadios de la sexualidad genital (clitoridiano y vaginal) y entendiendo que la fijación clitoridiana era algo a superar si quería hablarse de un adecuado desarrollo de la feminidad, dado que ésta implica que la niña da primacía a las tendencias pasivas de la constitución bisexual sobre las tendencias activas, propias del varón. Es bien cierto, sin embargo, que Deutsch ya fue entonces algo más allá que Freud en la consideración del desarrollo femenino de la sexualidad, pues consideró la intervención de componentes no sólo paternales y fálicos, sino también de raíz primariamente maternal: así, por ejemplo, interpretaba que la acción de la vagina en el coito, con la penetración del pene, era algo similar para la mujer a lo que sentía con la succión del pecho de la madre; también en el curso del acto sexual, decía Deutsch, la mujer se identifica con la imagen de la madre como víctima masoquista del padre (20). Aún con todo lo anterior, Deutsch daba a la figura paterna un papel muy importante, expresión quizás de sus propias conflictivas edípicas, estimando que los sentimientos positivos de una madre para con su hijo procedían en último término de su identificación con el padre idealizado por la madre durante su primera infancia (20).

En cuanto al parto, lo llegó a calificar como una orgía de placer masoquista, poniéndose en contra del uso de narcóticos para tener un parto sin dolor. En su línea de argumentación, Deutsch $(20,21)$ veía el embarazo, el parto y la crianza al pecho del hijo como la culminación del referido masoquismo femenino. 
HISTORIA

A mediados de 1924, Helene se trasladó de Berlín a Viena, reuniéndose con su marido e hijo (que había estado con ella en Berlín una temporada). En otoño de ese año tuvo lugar el asesinato de Hermine Hug-Hellmuth por su sobrino Rolf, lo que ocasionó un gran escándalo y un freno en el progreso el psicoanálisis infantil, ya que esta intervención fue muy criticada por considerarse peligrosa para el adecuado desarrollo del niño, abriéndose entonces un debate que alteró el avance de esta parcela del psicoanálisis.

Durante estos años el prestigio de Deutsch iba en aumento, llegando a encargársele la dirección del Instituto de Formación Psicoanalítica de Viena, recientemente fundado. Su compromiso con esta institución, en la que Anna Freud fue secretaria, se extendió hasta que se marchó a Estados Unidos en 1935, huyendo del nazismo y buscando un lugar en el que poder desarrollar sus ideas y su trabajo.

\section{Avances en el campo de la psico(pato)logía de la mujer}

En el campo de la psicología femenina, Deutsch mostró mucho interés por la génesis de la masculinidad y la feminidad en las mujeres, sistema sexo-género que inauguraba toda una línea de innovaciones psicoanalíticas. En lo que toca concretamente al lesbianismo, Freud (18) había atribuido la causa del mismo a la identificación de la mujer con el varón, como producto de un proceso defensivo contra el complejo de castración y la envidia del pene. Deutsch, por su parte, extendió tal proceso defensivo al rol de madre, en el sentido que también tendría un origen en la fijación masculina, cosa que defendió en el curso de una conferencia que dictó en Grecia sobre George Sand. En cuanto al asunto de la feminidad propiamente dicha, Helene mantuvo que la niña deseaba ser castrada por el padre tras la identificación con la madre, una especie de víctima masoquista del padre, cosa que explicaría la frecuencia de fantasías de violación de las jóvenes en la pubertad y en ocasiones pasividad, frigidez y pérdida de la autoestima en el momento de la madurez $(20,21)$. Además del masoquismo, un peculiar narcisismo sería el otro rasgo definitorio de la identidad femenina.

Todo ello fue ampliado en el curso del Congreso Internacional de Higiene Mental celebrado en 1930 en Washington, donde conoció a Franz Alexander que le ofreció, como a Karen Horney también invitada al congreso, un puesto de trabajo en Chicago. Esta última aceptó, pero no así Helene, que regresó a Viena y se puso a redactar su segundo libro, Psicoanálisis de las neurosis (21), sobre la base de las conferencias que había dictado en el Instituto de Formación Psicoanalítica de Viena, producto de su rica experiencia clínica. Aquí Deutsch trata de demostrar cómo los trastornos neuróticos no sólo poseen determinantes paternales, sino también maternales. Tuvo en cuenta, además, la acción de eventos problemáticos del presente, aunque sólo como agentes capaces de despertar pasada conflictivas infantiles (21). En todo caso, en estas problemáticas pudo ver con más claridad que Freud el papel que desempeñaba la madre, dada la mayor 
frecuencia de fenómenos transferenciales de esta raíz que tenía ocasión de observar por su condición de mujer (y por sus propias conflictivas infantiles), a pesar de que Freud opinaba que el sexo del terapeuta no influía en la transferencia.

La impotencia sexual y la frigidez, las fobias y las obsesiones, los celos, las depresiones, la homosexualidad y las alteraciones psicosomáticas fueron puestas bajo el nuevo prisma interpretativo, viéndose cada vez con más claridad la participación de la figura materna en todo ello, completando con ello la perspectiva freudiana en la que el padre estaba omnipresente y la madre apenas se consideraba.

De la serie de aportaciones que por entonces estableció Deutsch, tiene particular interés el enfoque que hizo del lesbianismo, pues aparte de enriquecer su conocimiento, contribuyó a ir sacándolo de la serie de prejuicios en que se hallaba envuelto. Al respecto, empezó a preparar una ponencia para el XII Congreso Internacional de Psicoanálisis que iba a celebrarse en 1931 y que fue aplazado por la crisis económica que sumía a Alemania. Por tal razón, el contenido fue presentado en la Asociación Psicoanalítica de Viena a comienzo del curso 1932-1933. En este trabajo Deutsch supera la interpretación de Freud, que explicaba el lesbianismo como el resultado de una inadecuada resolución tanto del complejo edípico como del complejo de castración, con la subsiguiente identificación de la niña con el padre en vez de con la madre (18). Al modo de ver de Deutsch, sin embargo, el lesbianismo era más bien un producto preedípico, donde la madre tenía el máximo protagonismo, a semejanza de lo que ocurre en el trastorno maniaco-depresivo (22). Para ella, sería el miedo a la pérdida de la madre la fuente principal del odio y la culpabilidad en la hija, alimentando estos sentimientos el establecimiento del lesbianismo y de diversas angustias genitales (23).

\section{Otras aportaciones originales al psicoanálisis: la personalidad "como si"}

Durante los años 1933 y 1934 Centroeuropa vivió la aparición y rápido ascenso del nazismo. Los psicoanalistas, tanto por la materia que trataban como sobre todo por ser la mayoría de ellos judíos, se vieron claramente amenazados. Deutsch, sin embargo, persistió por entonces en su trabajo y en sus investigaciones, redactando en enero de 1933 un interesantísimo artículo titulado El tipo psicológico "como si”, que se reeditó como Algunas formas de disturbios emocionales y su relación con la esquizofrenia (24), anomalía que hoy agrupamos bajo el epígrafe de trastorno narcisista de la personalidad.

El papel de la identificación con la madre, sin obviar la ya conocida acción del padre, pasó a tener en el anterior artículo de Deutsch una función primordial en el desarrollo humano normal y anómalo. En tal línea, puso en evidencia la existencia de un trastorno límite entre la neurosis y la psicosis, la referida personalidad "como si", en donde el sujeto tiene una conducta aparentemente normal, pero cuyas emociones y moral tienen un carácter superficial y meramente formal, lo que ponía en conexión con una falta 
HISTORIA

de adecuada vinculación edipiana en la primera infancia con una de las figuras parentales, de forma que no se instaura ninguna estructura superyoica estable, subordinándose el sujeto a una autoridad externa, creando relaciones con los otros emocionalmente muy laxas, superficiales y poco duraderas $(24,25)$. Helene presentó en el XIII Congreso Psicoanalítico Internacional celebrado en 1934 en Lucerna (Suiza) una comunicación sobre tal tipo de personalidad, tomando como ejemplo a Don Quijote, que era identificado con una imagen heroica idealizada del padre, mientras que Sancho Panza representaría el modelo maternal (25).

Estados Unidos, un refugio feliz, donde pudo cuajar su libro más importante, Psicología de la mujer

Dada la evolución que el nazismo iba teniendo en Europa, los esposos Deutsch deciden finalmente emigrar a Norteamérica, lo que se vio facilitado por la agradable acogida que habían tenido el año 1933 cuando ambos dieron un ciclo de conferencias en Nueva York. A Freud le desagradó la decisión, diciéndole a Helene que siempre la querría, pero que no le perdonaría jamás el que se fuera a Estados Unidos, país hacia el que siempre sintió un cierto grado de desprecio. Pero la decisión estaba tomada: primero se trasladó Felix, que llegó a Boston a primeros de 1935, negociando la posibilidad de instalarse ambos en la clínica psiquiátrica que había fundado Stanley Cobb el año anterior y aunque éste era un escéptico del psicoanálisis, fue conquistado por la belleza de Helene, manifestando que tenía que confiar en una mujer que tenía tan bellos ojos (12). Tras ello, Felix regresó a Viena, volviendo a Norteamérica definitivamente a principios de 1936, cuando su mujer ya estaba instalada en EE UU.

En efecto, en septiembre de 1935, Helene y su hijo Martin embarcaron hacia Nueva York, a donde llegaron el 24 de ese mes, siendo recibidos por Radó, Wittels y Nunberg. Madre e hijo fijaron su residencia en Boston, donde, a pesar de sus reticencias iniciales, Helene se adaptó con rapidez y fue feliz, mostrándose incluso crítica con lo que había dejado en Europa. Sólo los problemas con su hijo Martin le amargaban algo su existencia, por lo que decidió que éste viviera solo en un apartamento, a pesar de que únicamente tenía dieciocho años. Poco a poco, sin embargo, Martin se fue asentando, llegando a ser profesor de física nuclear tras superar sus estudios universitarios en el Instituto Tecnológico de Massachusetts (MIT), contrayendo matrimonio en 1939 con Suzanne Zetlin. Nunca llegó a tener unas buenas relaciones con su madre (12).

En 1936 (en agosto de este año también el matrimonio se permitió un corto viaje a Europa, para asistir al Congreso Psicoanalítico de Marienbad) los Deutsch compraron una casa en Cambridge, donde Helene instaló su consulta privada. Por entonces, Felix vivía en San Luis, donde había sido nombrado profesor de medicina psicosomática, permaneciendo allí hasta 1941. Dos años antes habían adquirido una granja en New Hampshire, a la que llamaron Babayaga, palabra polaca que significa bruja buena, donde Helene pasaba su tiempo libre trabajando la tierra. 
El prestigio de Helene en Estados Unidos fue en rápido aumento, siendo nombrada en 1944 psiquiatra asociada en el Hospital General de Massachusetts. Poco después empezó a elaborar su obra cumbre, La psicología de la mujer (26), que tenemos en traducción española en dos volúmenes bajo los auspicios de la editorial Losada.

Freud se había acercado a la mujer, el continente negro, con una perspectiva un tanto machista, idealizándola en tanto madre y repudiándola en tanto una especie de varón castrado. Por el contrario, Helene la abordó desde la propia visión femenina, aunque limitándose a estudiarla a partir de la juventud, dando en todo caso excesivo acento al narcisismo, la pasividad y el masoquismo, así como al papel de la maternidad en el curso del desarrollo. En el primero de los tomos de La psicología de la mujer, Deutsch (26) argumenta que la principal fuente de influencia sobre la psicología adolescente de la chica era la madre y no el padre, concediendo igualmente una importancia notable a las amistades, sobre todo a la hora de resolver la cuestión de la identidad sexual, señalando también que tales amistades podían ser fuente de desajustes importantes en los casos de rupturas inesperadas. Por otro lado, la aparición de la menarquia sirve de trampolín para hacer saltar las quejas de la joven respecto a su madre, pues hace responsable a ésta de ocultarle una serie de secretos. Las primeras menstruaciones también reavivan culpas masturbatorias, así como temáticas masoquistas conectadas con el coito y el parto (26). En el desarrollo femenino, la conflictiva preedípica se reeditaría durante la prepubertad, con el intento de la chica de liberarse de sus constituyentes, particularmente del lazo más potente que la une al pasado, la madre, ligazón que nunca se pierde totalmente, representando ello un factor muy significativo en todas las etapas de la vida de la mujer. Ahora bien, si fracasa el intento de romper en un grado suficiente la adhesión a la madre, la joven tenderá a establecer relaciones afectivas marcadas por la dependencia emocional y por una constante necesidad de apoyo, llevando en ocasiones sus demandas a la imposibilidad de su total satisfacción (26).

En otro orden de cosas, si bien para Deutsch hay una etapa de actividad propia de la pubertad para ambos sexos, en la niña el impulso a la actividad es más débil y la inhibición externa más fuerte, sobre todo en lo que se refiere a los componentes agresivos de tal actividad. Tal inhibición acontecería, sin embargo, desde lo social y no desde lo anatómico-constitucional, naciendo de una transacción con el medio cultural que a cambio de las renuncias de la chica le ofrece como pago el ser amada, en lo cual estaría una de las fuentes del masoquismo femenino: una vuelta contra sí de su reprimida hostilidad. Entiende igualmente Deutsch que esta prioridad por ser amada conduce a las mujeres a renunciar muchas veces a sus propios juicios, buscando la aprobación y la satisfacción narcisista a través de la complacencia al varón (26).

En cuanto al masoquismo de la mujer, Deutsch (26) lo correlaciona con la pasividad femenina, que no sólo vendría de la fuente constitucional, sino también de la social, como acabamos de referir, conformándose como un rasgo típico de la psicología femenina la atracción por el sufrimiento. También estableció que, cuando existe un masoquismo patológico, se concretan tres tipos psicológicos de mujeres a la hora de 
HISTORIA

relacionarse con el hombre: el primero, aunque bajo la protección de una coraza narcisista, supone una persona muy vulnerable a la agresividad del hombre; el segundo tipo, que aún es más narcisista que el anterior, es de difícil acceso o conquista; el último tipo sería la masoquista carcomida por la culpabilidad que elige una pareja siguiendo el modelo del padre protector y que muestra una sexualidad inhibida. Este último tipo suele pertenecer al círculo obsesivo, mientras que los dos primero son más bien del círculo histérico.

En el tema de la pasividad femenina en la sexualidad, Deutsch, aunque incluyó el determinismo socio-culrural, no abandonó las explicaciones de tipo biologista, manteniendo que dado que la vagina no es un órgano activo, dependiendo completamente de la actividad del hombre, tal hecho anatomo-fisiológico serviría de fundamento para ir creando en la mujer actitudes pasivas diversas, tesis que fue rechazada tanto por Karen Horney como por Melanie Klein. En cuanto a la influencia de algunos factores socio-culturales, entendió que restringían normativamente a que la mujer adoptase posiciones activas en la sexualidad y en los comportamientos agresivos en general (26). En todo caso, la mujer es descrita por Deutsch como pasiva y masoquista, una culminación de lo cual sería la prostitución fantaseada o real, producto de la identificación con una madre víctima consentida de un padre cruel. La rebeldía de las jóvenes la consideraba como producto de una reacción contra tal modelo identificativo, al igual que el lesbianismo, que era explicado como una protesta contra el papel humillante de la madre ante el padre (26).

El segundo tomo de La psicología de la mujer, está fundamentalmente dedicado a temas conectados directa o indirectamente con la maternidad. Deutsch (26), fundamentándose en determinantes biológicos, socio-históricos, antropológicos y psicológicos, aborda el hecho de la maternidad como algo que, en primer término, puede significar para la mujer la eventual destrucción de su sexualidad; pero también, en segundo término, un camino para contrarrestar la pasividad y el masoquismo. Por ello, algunas jóvenes, sobre todo cuando carecen de un modelo adecuado de madre, precipitan su maternidad, tratando así de superar algunas de sus conflictivas, especialmente el rechazo del modelo materno. Serían muchos de los casos de los embarazos no deseados de las adolescentes, tema tan en boga en la actualidad.

En este mismo marco, Deutsch abordó el asunto de la esterilidad psicógena de la mujer: el odio de la hija por la sexualidad de la madre ocasiona una inhibición inconsciente de la gestación, así como una actitud de infantil dependencia respecto a la pareja, siendo el esposo paralelamente considerado como una especie de hijo. También existen mujeres que rechazan la maternidad porque ésta pone en peligro su masculinidad, aunque paradójicamente algunas de ellas se sienten realizadas en su masculinidad precisamente teniendo un hijo, que de alguna manera les aporta el envidiado pene (26). 
En lo que toca al embarazo, Deutsch mantuvo que algunas mujeres se sienten justificadas de sus pasadas culpas por medio de la gestación, mientras que otras la ven como el camino para alejarse de la madre y lograr la plena autonomía, aunque algunas de ellas retornan finalmente a la completa dependencia de ella tras el nacimiento del hijo (26).

Un capítulo que interesó mucho a Deutsch fue el de los falsos embarazos (ella y su nuera aquejaron esta psicopatología): la ambivalencia ante la maternidad, el deseo y el rechazo de ser madre, sería la fuente de este trastorno, en el que los temores mágicos a las consecuencias del parto también tendrían un considerable papel, así como el temor a la pérdida de la propia individualidad al poder quebrarse el desarrollo de la autonomía. Es bien cierto, sin embargo, manifestó Deutsch, que algunas mujeres enriquecen su narcisismo tras tener un hijo (26). En este sentido, Helene atendió a la influencia de los factores socio-culturales en el aumento de la autoestima ligado a la maternidad, resaltando la necesidad de abrir otras vías alternativas para aumentar tal autoestima. También hizo interesantes consideraciones en torno a las madres solteras y las madres adoptivas.

Finalmente, Deutsch abordó aspectos psicológicos ligados a la menopausia, describiendo las rivalidades entre suegra y nuera en lo que concierne a las relaciones con el nieto e hijo, respectivamente. Subrayó la necesidad de que la abuela-suegra abandonase sus deseos de repetir el papel de madre con los nietos, así como evitar las rivalidades con la nuera (26).

\section{Últimas aportaciones en torno a los trastornos de la personalidad y las neurosis}

En el terreno de la psicopatología, Helene también investigó las imposturas y otros trastornos de la personalidad, sobre todo los derivados del narcisismo, lo que le interesó especialmente a partir del 2 de enero de 1964, fecha de la muerte de su marido. Así, en un ensayo dedicado a la amnesia postraumática (27), se centró en las problemáticas ligadas al narcisismo y un año después escribe acerca del papel del deporte como camino resolutivo de ciertas conflictivas narcisistas (28). También siguió dedicando mucho tiempo a los estudios sobre la adolescencia, describiendo particularmente al joven que adopta los ideales del padre como suyos y que construye su vida en función de la identificación con tal progenitor (29). Sin duda hablaba de ella misma. Algún tiempo antes, a mediados de la década de los sesenta, Deutsch saca a la luz Neurosis y tipos de carácter (30), cuya primera parte era una reedición de su Psicología de las neurosis, y la segunda parte una serie de escritos clínicos elaborados desde 1919 hasta 1963, en los que se vuelve a ocupar de la homosexualidad en la mujer, la maternidad y la sexualidad, la frigidez, una contribución de la psicología del ego al tipo psicopático y otros temas relacionados con sus dedicaciones anteriores.

Ya en su etapa de decadencia, presentó en el Instituto Psicoanalítico de Nueva York, a finales de los sesenta, Un estudio psicoanalítico del mito de Dionisos y Apolo (31) y cuatro años después aparecerá su última publicación, una especie de autobiografía 
HISTORIA

titulada Confrontaciones con mi self (9), que ella misma estimó como una prolongación de La psicología de la mujer. Entre otras confesiones, Helene afirma aquí que se había liberado de la influencia de su madre gracias a tres hombres: su padre, Herman Lieberman y Sigmund Freud. Su marido no estaba en la lista. Además manifestó que los grandes episodios de su vida fueron, además de la referida ruptura con la madre, el acercamiento a la revolución socialista y la liberación de las cadenas del inconsciente a través del psicoanálisis.

El 29 de marzo de 1982, a los 98 años de edad, Helene Deutsch falleció en su hogar en un estado senil, hablando ya sólo polaco y confundiendo en sus recuerdos a su esposo con Herman Lieberman, según ha contado su hijo Martin (16).

\section{A modo de síntesis}

Helene Deutsch fue, en resumen, una mujer comprometida con la emancipación de su género, aunque teniendo que vencer su fidelidad a las conservadoras teorías de Freud, que sin embargo supusieron para ella una fuente de revolucionaria liberación, abriéndole la posibilidad de delimitar una identidad peculiar en la mujer, si bien con algunas de las limitaciones que su relación con el maestro y sus propias conflictivas le habían impuesto, como podría ser un reprimido lesbianismo, que aparece más o menos solapadamente en sus aportaciones teóricas y en su biografía (como, por ejemplo, su elección de pareja y las problemáticas con su maternidad). Algunas de tales contradicciones son patentes en su Psicología de la mujer, que está saturada de su propia experiencia con la feminidad (16), por todo lo cual sufrió el rechazo de gran número de feministas de la década de los sesenta y setenta que entendían que Helene describía una inadecuada identidad femenina, producto de una pasiva dependencia del varón, especialmente de la figura paterna o sus sustitutos, y sólo centrada en una autocomplacencia narcisista sobre la belleza física o la elegancia. Frente a ello, otras feministas asumieron con respeto sus ideas, como es el caso de Simone de Beauvoir (32). 
HISTORIA

\section{BIBLIOGRAFÍA}

(1) Horney, K. "Book Review of H. Deutsch, Psychoanalysis of Sexual Women". International Journal of Psychoanalysis, 1926, 7, 92-100.

(2) Thompson, C. "Pennis-envy". En H. M. Ruitembek (ed.), Psychoanalysis and Female Sexuality. New Haven, CT: College University Press, 1967, 246-251.

(3) Erikson, E. Womanhood and the inner space. En J. Strouse (ed.), Women and Analysis. New York: Grossman, 1974, 291-319.

(4) Friedan, B. The Feminine Mystique. New York: Norton. 1963

(5) Bardinter, E. L'amour en plus. Histoire de l'amour maternel, XII-XIX siècle. Paris: Flammarion. 1980

(6) Levinton, N. El superyó femenimo. La moral en las mujeres. Madrid: Biblioteca Nueva. 2000

(7) Briehl, M. H. Helene Deutsch. En M. Grotjahn y otros, Historia del Psicoanálisis, IV. Buenos Aires: Paidós, 1968, 79-104.

(8) Miñarro, A. Helene Deutsch (Rosenbach): deseo, femineidad y revolución. Tres al cuarto, 3. Las fronteras de la ética, 1997. 6-8.

(9) Deutsch, H. Confrontations with Myself. New York: Norton. 1973

(10) Freud, S. Der Wahn und die Traume in W. Jensen "Gradiva". Lepizig und Wien: H. Heller. 1997. Traducción española: El delirio y los sueños en la "Gradiva" de W. Jensen. En Obras Completas IX. Buenos Aires: Amorrortu, 1979, 3-80.

(11) Freud, S. Die Traumdeutung. Leipzig und Wien: Franz Deutiicke. 1900. Traducción española: La interpretación de los sueños. En Obras Completas, IV y V. Buenos Aires: Amorrortu, 1979.

(12) Sayers, J. Les mères de la psychanalyse. Paris: PUF, 1995.

(13) Andreas-Salomé, L. "Anal" und "sexual". Imago, 1916. IV, 5, 249-253.

(14) Roudinesco, É. y Plon, M. Dictionnaire de la psychanalyse. Paris: Fayard. 1997. Traducción española: Diccionario de psicoanálisis. Buenos Aires: Paidós, 1998.

(15) Roazen, P. Brother Animal: The Story of Freud and Tausk. New York: Knopf. 1969. Traducción españñola: Hermano animal. La historia de Freud y Tausk. Madrid: Alianza, 1973.

(16) Roazen, P. Helene Deutsch. A Psychoanalytic Life. London: Transaction Publishers. 1985

(17) Deutsch, H. Psychoanalysis of the Sexual Functions of Women. London: Karnac Books, 1991.

(18) Freud, S. Über die Psychogenese eines Falles von weiblider Homosexualität. Internationale Zeitschrift für Psychoanalyse, 1920. 6-1, 1-24. Traducción española: Sobre la psicogénesis de un caso de homosexualidad femenina. Obras Completas, XVIII. Buenos Aires: Amorrrortu, 1979, 137-164.

(19) Freud, S. Über die Weibliche Sexualität. Internationale Zeitschrift für Psychoanalyse, 1931. 17, 3, 317-332. Traducción española: Sobre la sexualidad femenina. En Obras Completas, XXI. Buenos Aires: Amorrortu, 1979, 223-244.

(20) Deutsch, H. The Significance of Masoquism in the Mental Life of Women. En R. Fliess, The Psychoanalytic Reader. London: Hogarth Press, 1950.

(21) Deutsch, H. Psychoanalysis of the Neuroses. En Neuroses and Character Types. New York: International Universities Press, 1965, 3-158.

(22) Deutsch, H. The Psychology of Manic-Depressive States. En Neuroses and Character Types. New York: International Universities Press, 1965, 203-217. 
HISTORIA

(23) Deutsch, H. Die Verleugnung der Vagina. Ein Beitrag zur Frage der spezifisch weiblichen Genitalangs. Internationale Zeitschrift für Psychoanalyse, 1933, 372-384. Traducción española: La negación de la vagina. Contribución al problema de las angustias genitales específicas de las mujeres. En Psicología femenina. Buenos Aires: Psique, 1970, 167-182.

(24) Deutsch, H. Some Forms of Emotional Disturbances and their Relationship to Schizophrenia. En Neuroses and Character Types. New York: International Universities Press, 1965, 262-281.

(25) Deutsch, H. Don Quixote and Quixotism. En Neuroses and Character Types. New York: International Universities Press, 1965, 218-225.

(26) Deutsch, H. The Psychology of Women, 2 vols.. New York: Grune \& Straton. 1944-1945. Hay traducción española: La psicolog.ía de la mujer, 2 tomos. Buenos Aires: Losada, 1977.

(27) Deutsch, H. Posttraumatic Amnesia, and their Adaptative Function. En R. M. Lewenstein, Psychoanalysis. New York: International Universities Press. 1966

(28) Deutsch, H. Some Factors in Sport. En R. Stovenko y J. Knight, Motivarion in Play, Games and Sports. Springfield: Tomas, 1967. 91-94.

(29) Deutsch, H. Selected Problems in Adolescent. New York: International Universities Press. 1967

(30) Deutsch, H. (1965). Neuroses and Character Types. New York: International Universities Press. 1965

(31) Deutsch, H. A Psychoanalytic Study of the Myth of Dionysus and Apollo. New York: International Universisties Press. 1969

(32) Beauvoir, S. Le deuxième sexe, 2 vols.. Paris: Gallimard. 1949. Traducción española: El segundo sexo, 2 vols. Valencia: Cátedra, 1989.

*Facultad de Psicología. Universidad de Sevilla

C/. Camilo José Cela, s/n

41018 - Sevilla

Recibido: 25-09-02 